\title{
THE SITES OF THE SPERMICIDAL ACTION OF ETHYLENE DIBROMIDE IN BULLS*
}

\author{
D. AMIR \\ Division of Animal Reproduction, Agricultural Research Organization, \\ The Volcani Center, P.O.B. 6, Bet Dagan, Israel
}

(Received 29th November 1972)

\begin{abstract}
Summary. Sperm smears prepared from different parts of the genital tract of two bulls 12 and 21 days after the start of oral treatment with ethylene dibromide ( $4 \mathrm{mg} \mathrm{EDB} / \mathrm{kg}$ body weight on alternate days), showed a distribution of abnormal spermatozoa, which indicates that EDB affected the shape of the spermatozoa during maturation in the epididymis and during spermiogenesis.

After administration to four bulls of labelled $\left[{ }^{3} \mathrm{H}\right]$ - or $\left[{ }^{14} \mathrm{C}\right] \mathrm{EDB}$, either orally or by injection, labelled spermatozoa were obtained in the ejaculates collected from about 1 week after the first oral dose or injection until 2 to 3 weeks after the last oral dose or injection. The highest percentage of abnormal spermatozoa resulting from the treatment was found when the radioactivity of the spermatozoa was lowest or nil.

It appears that the spermicidal action of EDB is not direct on the sperm cells but occurs during the process of spermiogenesis and through the absorptive and/or secretory functions of the epididymis.
\end{abstract}

\section{INTRODUCTION}

Ethylene dibromide (EDB) administered orally to bulls in ten doses of $4 \mathrm{mg} / \mathrm{kg}$ body weight, or a single injection of about $100 \mathrm{mg}$ EDB into the peritoneal fluid which surrounds each testis, was found to induce temporary malformations up to total disintegration of the sperm cells in the ejaculates collected from about 2 weeks after the start of either treatment (Amir \& Volcani, 1965; Amir \& BenDavid, 1973). It was suggested (Amir \& Ben-David, 1973) that this effect was caused by this compound during the processes of spermiogenesis and sperm maturation.

In the present work, an attempt was made to examine the above suggestion. The distribution of sperm abnormalities in the genital tract of bulls after different periods of oral treatment with EDB was followed and the labelling pattern of spermatozoa, sperm fluids and genital tract tissues after the administration of labelled EDB either orally or by injection was studied.

* Contribution from the Agricultural Research Organization, The Volcani Center, P.O.B. 6, Bet Dagan, Israel. 1972 Series, No. 2216-E. 


\section{MATERIALS AND METHODS}

Six Israeli-Friesian bulls, 15 to 20 months old and with a body weight of 450 to $550 \mathrm{~kg}$, were used. These animals were maintained on a roughage-concentrates ration.

Two bulls were treated orally with EDB diluted in olive oil at a concentration of $200 \mathrm{mg} / \mathrm{ml}$. Doses containing $4 \mathrm{mg} \mathrm{EDB} / \mathrm{kg}$ body weight were given in gelatin capsules with a ball-gun on alternate days. One of the bulls was slaughtered 12 days after the start of the treatment (after seven doses of EDB) and the second one was castrated 21 days after the start of the treatment, or 3 days after the end of a ten-dose treatment. Smears of spermatozoa from the testis, different parts of the epididymis, and the ductus deferens were prepared and stained with Giemsa stain. The percentages of abnormal spermatozoa and of sperm abnormalities were recorded by observing at least 400 spermatozoa at random, under an immersion objective $(\times 1000)$.

Tritium-labelled EDB (1,2-T, 0.22 to $2.2 \mathrm{mCi} / \mathrm{mmol}$; Nuclear Research Center, Israel) was diluted as above in olive oil $\left(0.234 \mathrm{mCi}\left[{ }^{3} \mathrm{H}\right] \mathrm{EDB} / \mathrm{ml}\right)$. Ten doses of $10 \mathrm{ml}(2 \mathrm{~g} \mathrm{EDB}, 2.34 \mathrm{mCi})$ were given on alternate days in gelatin capsules to one bull. A second bull was anaesthetized and injected with $0.6 \mathrm{ml}$ $(120 \mathrm{mg} \mathrm{EDB}, 1.4 \mathrm{mCi})$ into the peritoneal cavity beneath the tunica vaginalis of each testis (Amir \& Ben-David, 1973). Two other bulls were similarly injected with $1 \mathrm{mCi}\left[{ }^{14} \mathrm{C}\right] \mathrm{EDB}$ ( 1 to $10 \mathrm{mCi} / \mathrm{mmol}$; Radiochemical Centre, Amersham, Bucks., U.K.) in 220 and $350 \mathrm{mg} \mathrm{EDB}$, respectively, and in $1.2 \mathrm{ml}$ olive oil.

One and occasionally two ejaculates were collected with an artificial vagina two to three times a week before, during, and for 2 to 3 months after, the treatment. As with the smears prepared from the genital tract of the first two bulls, the percentage of abnormal spermatozoa was calculated from smears stained with Giemsa stain.

The seminal plasma was separated by centrifugation (1500 $\mathrm{g}$ for $10 \mathrm{~min}$ ) and the spermatozoa were resuspended with $10 \mathrm{ml} \mathrm{0.9 \%} \mathrm{NaCl}$. After a second centrifugation, the supernatant was discarded and the spermatozoa were resuspended with $0.9 \% \mathrm{NaCl}$ to a concentration of $1 \times 10^{9}$ cells $/ \mathrm{ml}$. Preliminary experiments showed that this single washing removed practically all the remains of the measurable radioactivity in the seminal plasma. A $0.5-\mathrm{ml}$ vol. of Packard's 'Soluen ${ }^{\text {tm }} 100$ ' was added to $0.2 \mathrm{ml}$ seminal plasma and $0.1 \mathrm{ml}$ sperm suspension in duplicate scintillation vials and left overnight at room temperature. Bray solution $(10 \mathrm{ml})$ was added to each vial on the next day and the radioactivity was measured in a Packard Tri-Carb liquid scintillation spectrometer (model $314 \mathrm{Fx}$ or 574 ) for 10 or $20 \mathrm{~min}$. The samples of one bull only were corrected for quenching by the use of an internal standard from the injected sample. Since the quenching with either plasma or spermatozoa was found to be very low $(1.0 \%$ and $2.3 \%$ of the total count on the average, for the plasma and spermatozoa, respectively) this procedure was discontinued.

Two days after the last oral labelled dose, or 4 days after the injection, three of the bulls were unilaterally castrated. Samples of the testis and of the proximal median and distal parts of the head of the epididymis were fixed in Bouin's fluid, embedded in paraffin wax and cut into $7-\mu \mathrm{m}$ sections. These histological 
sections were mounted on Ilford's coated slides and dipped in $\mathbf{K}_{5}$ (Ilford) emulsion for autoradiography. After exposure of 60 days, the slides were developed in an Amidol developer (Farragi, 1952) and stained with haematoxylin-eosin (testis) or haemalum stain (epididymis).

\section{RESULTS}

The distribution of abnormal spermatozoa in the testis and the epididymis of two bulls treated orally with EDB is shown in Text-fig. 1. On the 12th day after

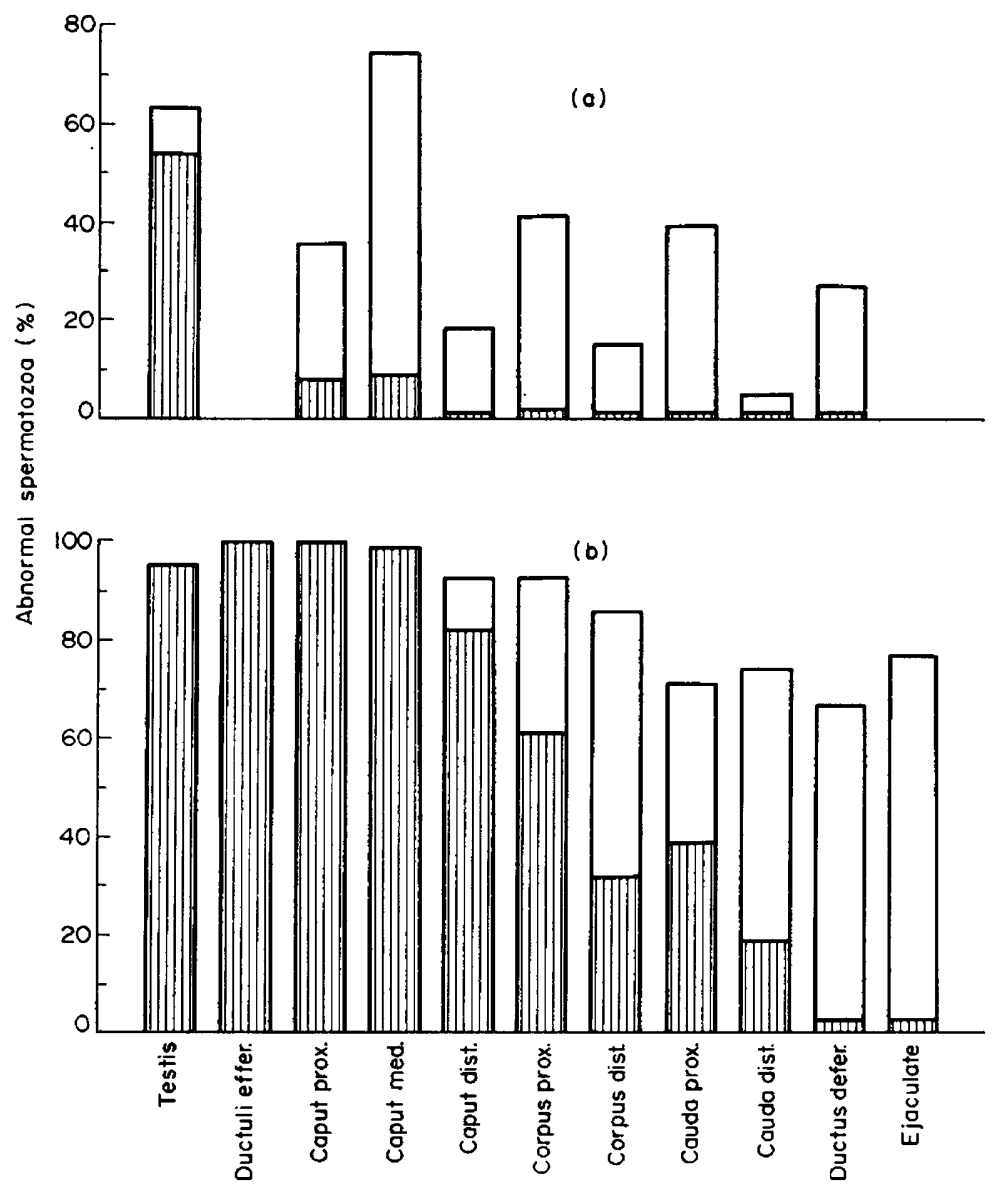

TexT-FIG. 1. The distribution of abnormal spermatozoa and sperm abnormalities in the genital tract of bulls 12 days (a) and 21 days (b) after the start of oral treatment with ethylene dibromide. Open columns = tail and acrosomal defects $;$ shaded columns = misshapen heads.

the start of the treatment, more than $50 \%$ of the spermatozoa in the testis and about $10 \%$ of the spermatozoa in the first two segments of the caput epididymidis had misshapen heads. The various segments of the epididymis contained different percentages of abnormal spermatozoa, almost all of which had tail and 
acrosome defects (Pl. 1, Fig. 1). On the 21st day after the start of treatment, the spermatozoa with misshapen heads constituted almost the entire sperm population of the testis and the caput epididymidis (Pl. 1, Fig. 2). In the corpus and the cauda epididymidis, these spermatozoa were found mixed with an increasing number of normal spermatozoa and spermatozoa with tail and acrosomal defects (Pl. 1, Fig. 3). These latter constituted almost the entire population of the $67 \%$ and $77 \%$ abnormal spermatozoa found in the ductus deferens (Pl. 1, Fig. 4) and the ejaculate, respectively, collected on that day.
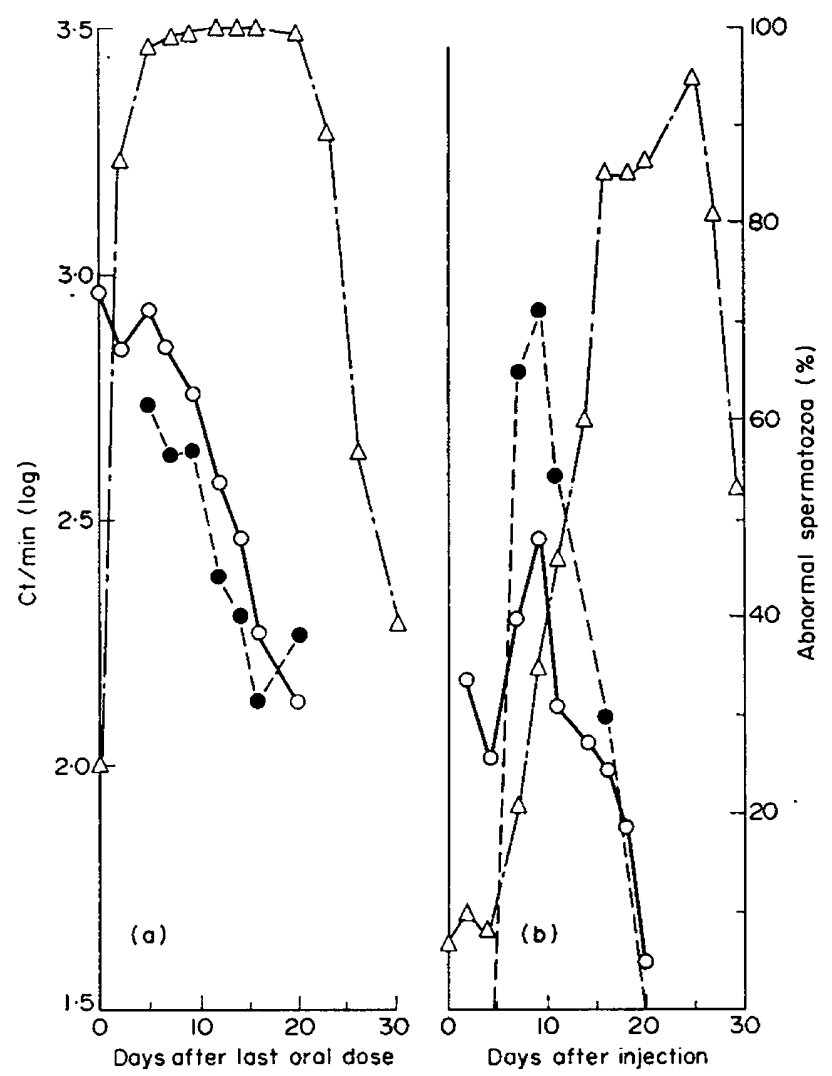

TEXT-FIG. 2. The rate of appearance of abnormal spermatozoa and of labelling intensity of the seminal plasma and of the spermatozoa in the ejaculates of bulls fed (a) or injected (b) with $\left[{ }^{3} \mathrm{H}\right]$ ethylene dibromide. $\Delta$, Percentage abnormal spermatozoa; $\bullet, \mathrm{ct} / \mathrm{min} / 1 \times 10^{9}$ spermatozoa; $O, \mathrm{ct} / \mathrm{min} / \mathrm{ml}$ seminal plasma.

The evolution of the percentage of abnormal spermatozoa and of the labelling intensity of the seminal fluids and of the spermatozoa in the ejaculates, after administration of $\left[{ }^{3} \mathrm{H}\right]$ - and $\left[{ }^{14} \mathrm{C}\right] \mathrm{EDB}$ orally and by injection, is presented in Text-figs 2 and 3.

The labelling intensity of the seminal fluids, after an initial decrease from the first to the second semen samples, increased to a maximum in the semen samples collected 3 to 5 days thereafter. Labelled spermatozoa appeared about 1 week 


\section{PLATE 1}

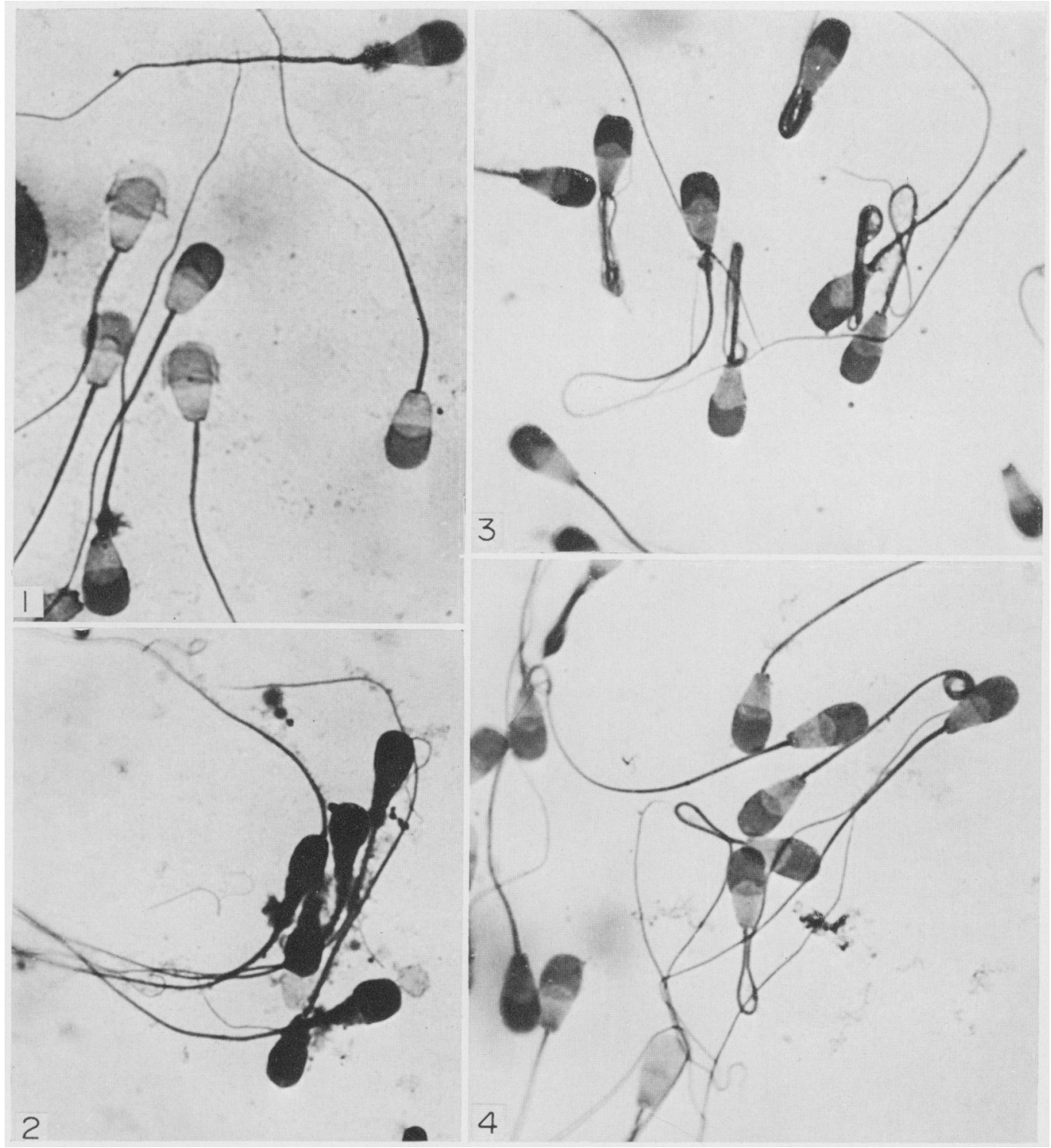

Smears from different parts of the genital tract of bulls treated orally with ethylene dibromide. Giemsa stain. $\times 1300$.

FIs. 1. Spermatozoa from the proximal part of the caput epididymidis 12 days after the start of the treatment; swelling and detachment of acrosomes.

Figs 2 to 4 . Spermatozoa from the genital tract of a bull 21 days after the start of treatment with EDB.

Fig. 2. Spermatozoa from the ductuli efferentia; misshapen, disintegrating heads.

Fig. 3. Coiled tails and pear-shaped heads of spermatozoa from the proximal part of the cauda epididymidis.

Fig. 4. Coiled tails and denuded heads of spermatozoa from the ductus deferens.

(Facing p. 522) 


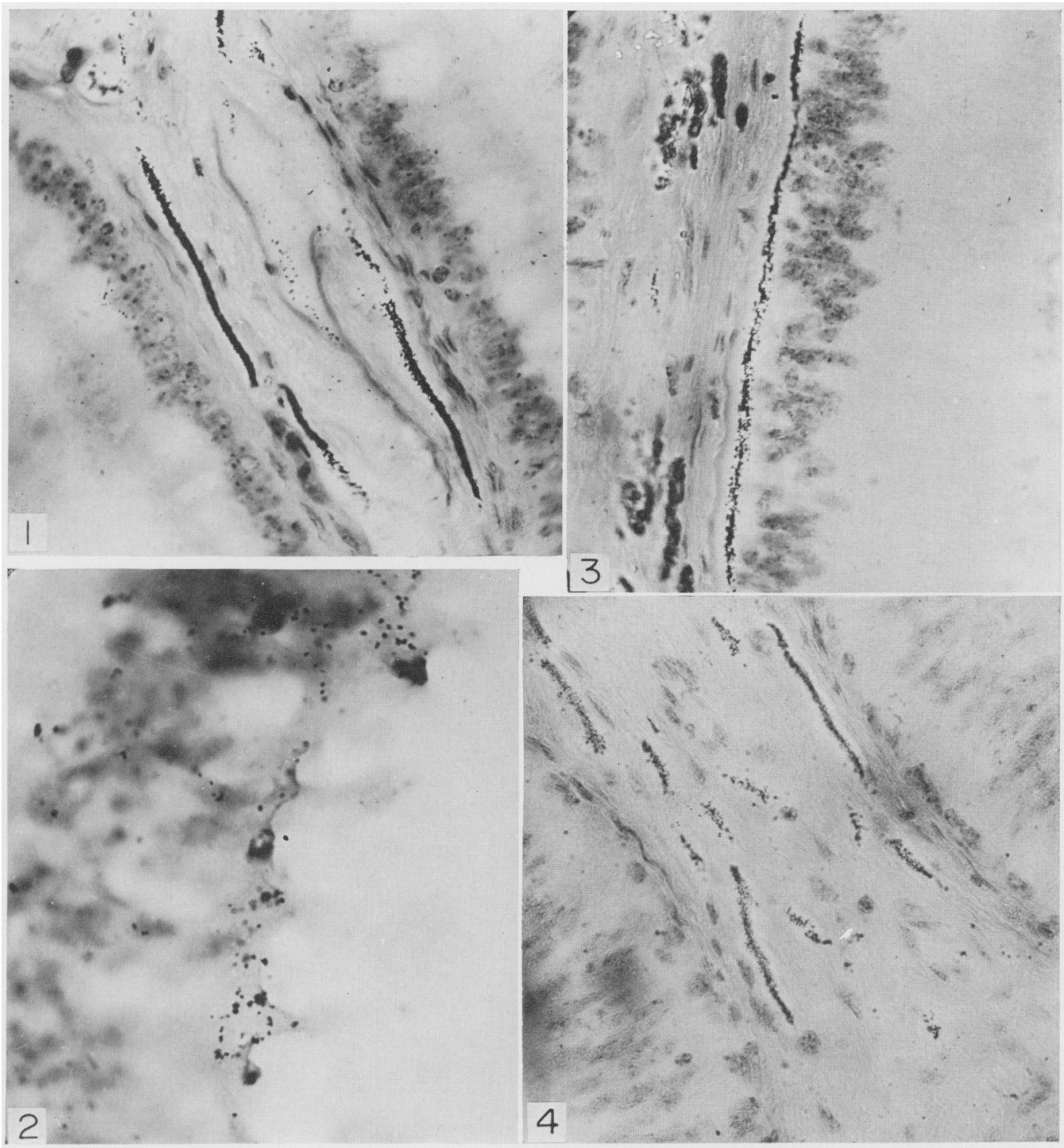

Autoradiographs of histological sections of the caput epididymidis of bulls treated with labelled ethylene dibromide; Mayer's haemalum stain.

FIgs 1 and 2. Sections of the proximal part of the caput epididymidis of a bull 2 days after the last oral dose of $\left[{ }^{3} \mathrm{H}\right] \mathrm{EDB}$. Labelling in the outer layer of the smooth muscle of the duct (Fig. $1, \times 600$ ) and in the stereocilia (Fig. 2, $\times 1200$ ).

FIG. 3. Section of the median part of the caput epididymidis of a bull 4 days after injection with $\left[{ }^{3} \mathrm{H}\right]$ EDB. Labelling in the basal cells, $\times 600$.

FIg. 4. Section of the distal part of the caput epididymidis of a bull 4 days after injection with $\left[{ }^{14} \mathrm{C}\right]$ EDB. Labelling in the smooth muscle of the duct, $\times 600$. 
after the labelled sperm fluids but the intensity of labelling evolved in a similar way to that of the fluids. The site of the spermatozoa in which the incorporation of the tracer took place could not be decected in the sperm autoradiographs due to the low specific activity of the spermatozoa (up to $2400 \mathrm{ct} / \mathrm{min} / 1 \times 10^{9}$ cells).

From Text-figs 2 and 3, it can also be seen that the percentage of abnormal spermatozoa resulting from the treatment increased while the intensity of the

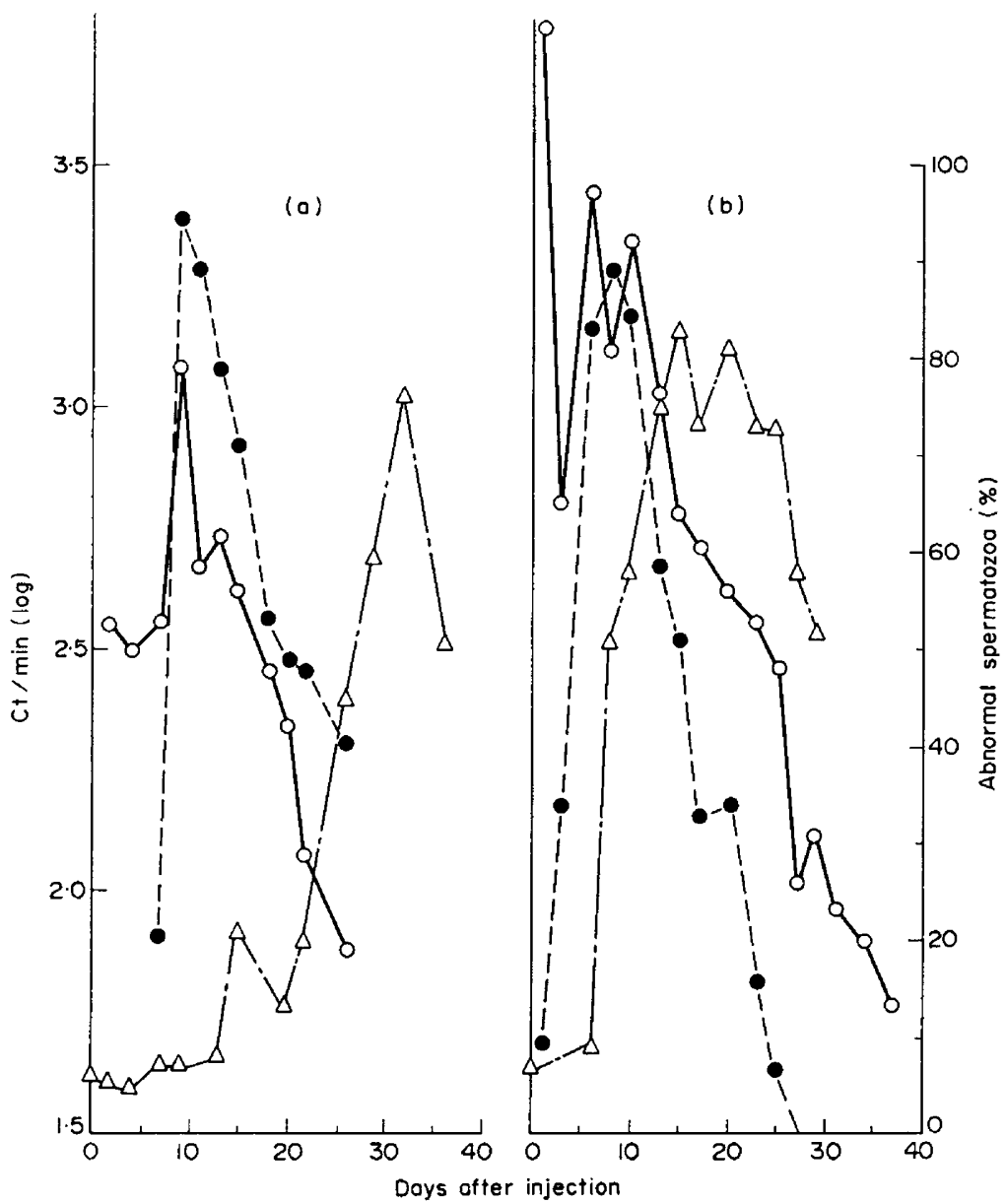

TexT-Fig. 3. The rate of appearance of abnormal spermatozoa and of labelling intensity of the seminal plasma and of the spermatozoa in the ejaculates of bulls injected with $\left[{ }^{14} \mathrm{H}\right]$ ethylene dibromide. $\Delta$, Percentage abnormal spermatozoa; $\bullet$, ct $/ \mathrm{min} / 1 \times 10^{9}$ spermatozoa; $O$, ct/min/ml seminal plasma.

labelling of spermatozoa decreased. The percentage of abnormal spermatozoa reached a maximal level when the radioactivity of the spermatozoa was minimal or not detectable.

Nolabelling could be detected in the autoradiographs of sections of the testes of the treated animals 2 and 4 days after the last oral dose or the injection, respectively, whereas in the sections of the caput epididymidis, labelling was seen in 
the basal cells and the smooth muscle which envelops the epididymal duct (Pl. 2, Figs 1,3 and 4 ), both when $\left[{ }^{3} \mathrm{H}\right] \mathrm{EDB}$ and $\left[{ }^{14} \mathrm{C}\right] \mathrm{EDB}$ were administered either by feeding or by injection. In one case, labelling was also seen in the stereocilia of the proximal part of the caput epididymidis (Pl. 2, Fig. 2).

\section{DISCUSSION}

From the distribution of sperm abnormalities in the genital tract of two bulls 12 and 21 days after the start of an oral administration of EDB, the spermatozoa with misshapen heads apparently originate from the testis under the influence of EDB and advance through the epididymis, gradually replacing the spermatozoa with tail and acrosomal defects. The latter defects probably originate in the epididymis, as was suggested in a previous study (Amir \& Ben-David, 1973). The action of EDB appears to be on the process of spermiogenesis and of sperm maturation and is not a direct effect on the spermatozoa, as was shown by the results obtained with labelled EDB.

Since the seminal plasma is composed of fluids from the epididymis and from other accessory glands, its radioactivity after treatment with labelled EDB must originate from one or both of these sources. The initial decrease in radioactivity from the first to the second sperm sample collected after administration of the last oral dose corresponds to the decreasing radioactivity of the blood, which was measured in one of the injected animals. The initial radioactivity of the seminal plasma can, therefore, be accounted for by the labelled fluids of the accessory glands. The radioactivity of the seminal fluids which increased to a maximal level about 1 week after the injection is probably due to the arrival of labelled epididymal fluids following a lapse of time needed for transit along the epididymal duct, or a part of it.

Labelled spermatozoa arrived in the ejaculates simultaneously with the labelled fluids from the epididymis, and their radioactivity may have been acquired from the epididymal fluids either by adsorption or by interaction(s) of the spermatozoa (or their contents) with these fluids. The possibility that some of the intracellular constituents of spermatozoa may be acquired from the epididymal secretion has been pointed out by Mann (1964).

In the four treated animals, labelled spermatozoa were found in the ejaculates collected 6 to 9 days after injection or the start of the oral treatment. Since the epididymal transit of bull spermatozoa was found to vary from 9 to 14 days, with an average of 11 days (Orgebin-Crist, 1962), the labelling of the spermatozoa may have occurred distally to the proximal part of the head of the epididymis.

Since the percentage of sperm abnormalities reached its highest level when practically no more sperm radioactivity could be detected, the detrimental effect of EDB on the structure of the spermatozoa does not seem to be a direct one through the interaction(s) of this compound with the spermatozoa (or their contents). It appears reasonable to assume that the interaction of this compound with the testicular and epididymal fluids caused disturbances in the normal process of spermiogenesis, probably by interference with the normal process of nuclear chromatin condensation (Gledhill, Darzynkiewicz \& Ringertz, 1971), 
and in the normal secretory and/or absorptive functions of the epididymis affecting the normal process of sperm maturation.

\section{ACKNOWLEDGMENTS}

This research was financed in part by a grant made by the United States Department of Agriculture under P.L. 480. The author is indebted to Dr A. Tadmor for the surgical work needed to inject the animals. The castrations of the animals were carried out by Dr A. Tadmor and Dr M. Davidzon. To Dr Hannah Broda, who prepared the histological sections, and to $\mathrm{Dr}$ T. Nobel for his advice, I express my appreciation. I am also grateful to Professor R. Ortavant and Professor G. M. H. Waites for reading the manuscript and for their valuable suggestions, and to $\mathrm{Dr} B$. P. Setchell for his interest. I wish to thank Mr M. Meidler for his technical assistance.

\section{REFERENCES}

AmiR, D. \& Ben-David, E. (1973) The pattern of structural changes induced in bull spermatozoa by oral or injected ethylene dibromide (EDB). Annls Biol. anim. Biochim. Biophys. 13, (2) (in press).

Amir, D. \& VolCANI, R. (1965) Effect of dietary ethylene dibromide on bull semen. Nature, Lond. 206, 99.

FARRAGI, H. (1952) Détection des éléments radioactifs par la technique photographique: autoradiographie. Commissariat dे l'Energie Atomique, France, p. 27.

Gledhill, B. L., Darzynkiewicz, Z. \& Ringertz, N. R. (1971) Changes in deoxyribonucleoprotein during spermiogenesis in the bull: increased $\left[{ }^{3} \mathrm{H}\right]$ actinomycin $\mathrm{D}$ binding to nuclear chromatin of morphologically abnormal spermatozoa. F. Reprod. Fert. 26, 25.

ManN, T. (1964) The biochemistry of semen and of the male reproductive tract. Methuen, London.

ORGEBIN-CRIst, M. C. (1962) Recherches expérimentales sur la durée de passage des spermatozoides dans l'épidididyme du taureau. Annls Biol. anim. Biochim. Biophys. 2, 51. 